Article

\title{
Quantitative Changes in the Transcription of Phytohormone-Related Genes: Some Transcription Factors Are Major Causes of the Wheat Mutant $d m c$ Not Tillering
}

\author{
Ruishi He ${ }^{1}$, Yongjing $\mathrm{Ni}^{2}{ }^{2}$, Junchang $\mathrm{Li}^{1}$, Zhixin Jiao ${ }^{1}$, Xinxin $\mathrm{Zhu}^{1}$, Yumei Jiang ${ }^{1}$, Qiaoyun $\mathrm{Li}^{1}$ \\ and Jishan $\mathrm{Niu}^{1, *}$ (10 \\ 1 National Centre of Engineering and Technological Research for Wheat/Key Laboratory of Physiological \\ Ecology and Genetic Improvement of Food Crops in Henan Province, Henan Agricultural University, \\ Zhengzhou 450046, Henan, China; guomai301@163.com (R.H.); chang_top@163.com (J.L.); \\ zxjiao2018@163.com (Z.J.); xzx1202@126.com (X.Z.); xinnercw@126.com (Y.J.); lqylhy@163.com (Q.L.) \\ 2 Shangqiu Academy of Agricultural and Forestry Sciences, Shangqiu 476000, Henan, China; nyj317@163.com \\ * Correspondence: jsniu@263.net
}

Received: 18 March 2018; Accepted: 26 April 2018; Published: 29 April 2018

Abstract: Tiller number is an important agronomic trait for grain yield of wheat (Triticum aestivum L.). A dwarf-monoculm wheat mutant $(\mathrm{dmc})$ was obtained from cultivar Guomai 301 (wild type, WT). Here, we explored the molecular basis for the restrained tiller development of the mutant $d m c$. Two bulked samples of the mutant $d m c$ (T1, T2 and T3) and WT (T4, T5 and T6) with three biological replicates were comparatively analyzed at the transcriptional level by bulked RNA sequencing (RNA-Seq). In total, $68.8 \mathrm{~Gb}$ data and 463 million reads were generated, $80 \%$ of which were mapped to the wheat reference genome of Chinese Spring. A total of 4904 differentially expressed genes (DEGs) were identified between the mutant $d m c$ and WT. DEGs and their related major biological functions were characterized based on GO (Gene Ontology) and KEGG (Kyoto Encyclopedia of Genes and Genomes) categories. These results were confirmed by quantitatively analyzing the expression profiles of twelve selected DEGs via real-time qRT-PCR. The down-regulated gene expressions related to phytohormone syntheses of auxin, zeatin, cytokinin and some transcription factor (TF) families of TALE, and WOX might be the major causes of the mutant $d m c$, not tillering. Our work provides a foundation for subsequent tiller development research in the future.

Keywords: wheat (Triticum aestivum L.); dmc mutant; transcriptome; tillering; differentially expressed genes

\section{Introduction}

Wheat (Triticum aestivum L.) is one of the most important food crops in the world. Since tiller number is an important agronomic trait for grain yield [1,2], it has always been one of the key traits to select in breeding programs. Generally, low and high tillering wheat mutants do not have very high grain yield. Moreover, tiller number as well as grain number and weight affect yield.

Mutants with various tillering abilities are ideal materials for the study of tiller developmental molecular mechanisms. Four tiller inhibition lines or mutants have been reported in wheat. Among the tiller inhibition genes, $\operatorname{tin} 1, \operatorname{tin} 3$ and $f$ tin are recessive, and they have been mapped on chromosome (Chr.) 1AS [3], 3A [1] and 1AS [4], respectively; tin2 is a dominant gene mapped on Chr. 2A [5]. One wheat high tillering mutant harbors a major quantitative trait locus (QTL; QHt.nau-2D) on Chr. 2DS [6]. In barley (Hordeum vulgare), the tiller inhibition genes lnt1, als1, cul4, int- $b$ and $u z u$ have 
been reported, and they have been mapped on Chr. 3HL [7], 3HL [8], 3HL [9], 5HL [9] and 3 HL [9], respectively. Many tiller related mutants have also been reported in rice (Oryza sativa) [10-12].

Tillering is a very complex trait; in addition to genetic factors, it can also be significantly affected by soil fertility and other environmental factors. Many studies showed that tillering is controlled by QTLs in wheat [13-16], rice [17-19], barley [20,21] and rye (Secale cereale) [22]. However, it is clear that some tiller traits are controlled by qualitative genes as described above. In Arabidopsis, the MORE AXILLARY GROWTH 1 (MAX1) genes encoding cytochrome P450 and MAX2 control shoot lateral branching [23,24]. The MAX4 genes encoding CAROTENOID CLEAVAGE DIOXYGENASE 8 (CCD8) and MAX3 genes encoding CCD7 regulate shoot branching [25,26]; MAX1 acts downstream of MAX3 and MAX4. The MAX1 genes are related to the strigolactone (SL) signaling pathway [24]. In comparison to the model species Arabidopsis, only a few genes affecting tiller initiation and outgrowth have been cloned and described in crops. For example, the rice gene MONOCULM 1 (MOC1) encodes a GRAS (GIBBERELLIC-ACID INSENSITIVE (GAI), REPRESSOR of GAI (RGA) and SCARECROW (SCR)) domain-containing protein that affects the initiation and outgrowth of axillary meristems $[27,28]$. Mutant lines that do not have a functional moc1 gene exhibit a severe reduction in tiller number. The rice gene Tillering and Dwarf 1 (TAD1), which encodes a multi-subunit E3 ligase, regulates rice tillering by degenerating MOC1 [29]. The rice TEOSINTE BRANCHED 1 (OsTB1) gene encodes a TCP domain protein and negatively regulates lateral branching [30]. In barley, the INTERMEDIUM-C (INT-C) gene is an ortholog of maize and rice TB1 genes which has an effect on seedling tiller number [31]. The barley $u z u$ gene encodes a putative brassinosteroid (BR) receptor HvBRI1 and regulates tiller number [32]. In bread wheat, overexpression of tae-miR156 significantly affects tillering, probably by regulating a group of SQUAMOSA PROMOTER BINDING PROTEIN-LIKE (SPL) genes; furthermore, miR156-TaSPLs and strigolactone signaling pathways might have a potential association with tillering [33]. Overexpression of the maize $t b 1$ gene in wheat results in reduced tillering [34]. The molecular mechanism of wheat tillering remains largely unknown.

At present, the RNA-Sequencing technique has been widely used to identify differentially expressed genes (DEGs) among various biological samples, so as to explore the possible mechanisms leading to various morphologies $[35,36]$. Transcriptome analyses regarding tiller developments in switchgrass (Panicum virgatum L.) and sorghum (Sorghum bicolor L.) have been reported [37-39]. In this study, a wheat mutant that does not develop tillers was obtained from the ethyl methanesulfonate (EMS)-treated wheat cultivar Guomai 301 (WT), which was designated as $d m c$ (dwarf-monoculm). We characterized the mutant $d m c$ and WT at the transcriptome level by RNA-sequencing technology.

\section{Results}

\subsection{Morphology of the dmc Mutant}

The mutant $d m c$ was obtained from wheat cultivar "Guomai 301" treated with EMS. Mutant $d m c$ basically does not tiller, and only has a main stem (Table 1, Figure 1A). Some individuals occasionally have a small tiller number. The plant height of the mutant $d m c$ was significantly lower than that of the WT, i.e., $48.00 \mathrm{~cm}$, which was $74.53 \%$ of the WT height (Table 1, Figure 1A). Both the spike length and the seed length of the mutant $d m c$ were shorter than those of the WT (Table 1, Figure 1B-D). The diameters of the internodes of the mutant $d m c$ were reduced (Figure 1E). The internode number of the mutant $d m c$ was four; however, that of the WT was five (Table 1, Figure 1F). Additionally, we continuously observed and compared the tillers of the mutant $d m c$ and WT from the early tillering stage. The mutant $d m c$ had no or one tiller at the early tillering stage (Figure $2 \mathrm{C}$ ), and it had no more tillers during the middle tillering period. Its tillering was significantly inhibited (Figure 2D). Generally, the mutant $d m c$ had only one main stem at the jointing stage (Figure 2E). The tiller primordia (Figure S1) were used as samples for transcriptomic analysis in this study. Tiller primordium samples were dissected at the three-leaf stage to four-leaf stage. Two super bulk samples of the mutant $d m c$ (T1, 
T2, and T3) and WT (T4, T5, and T6) with three biological replicates were prepared. Each bulk sample included more than ten independent individuals.

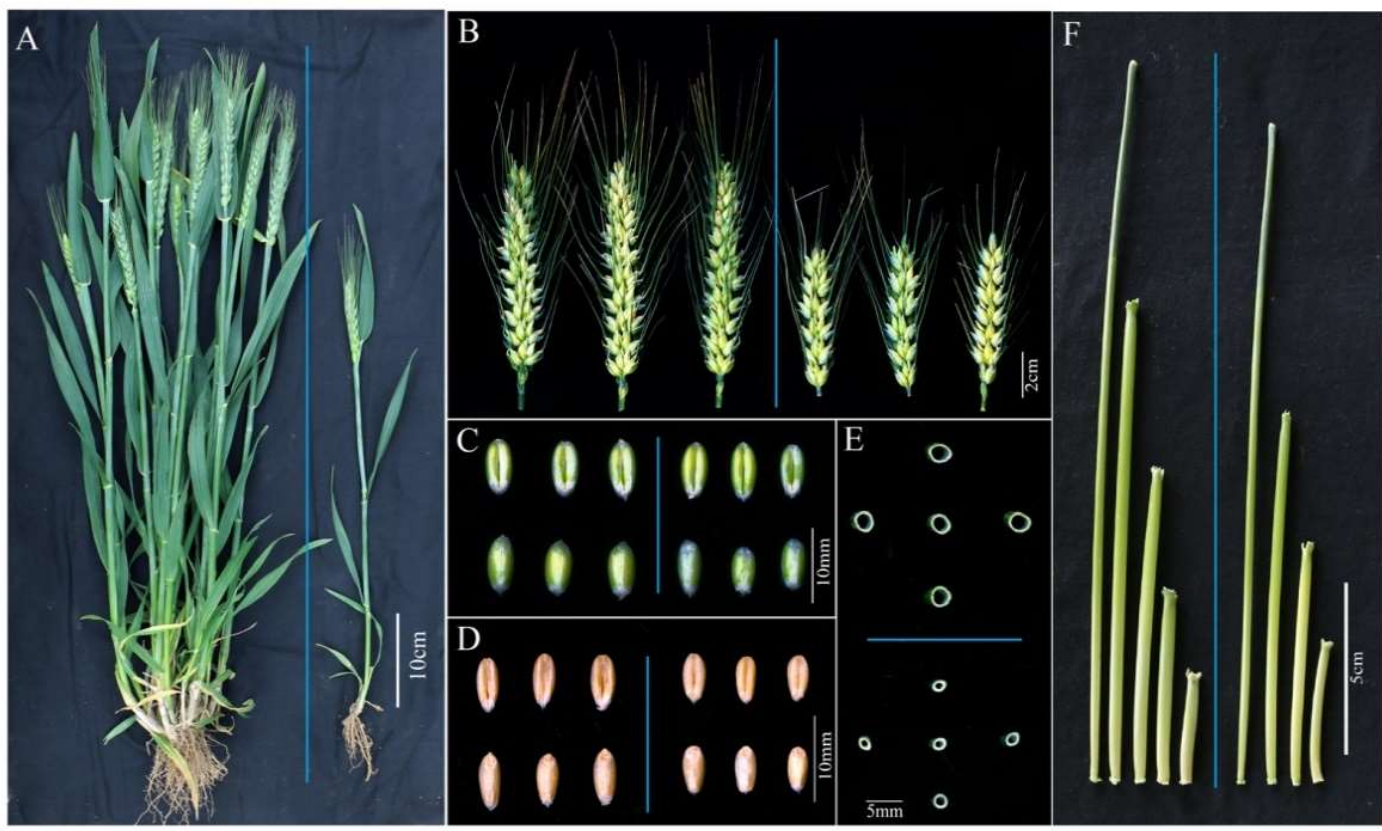

Figure 1. Comparison of agronomic traits between the WT and mutant $d m c$. (A) The plant phenotype of the WT (left) and mutant $d m c$ (right); (B) the spikes of the WT (left) and mutant $d m c$ (right); (C) the seeds of the WT (left) and mutant $d m c$ (right) at the filling stage; (D) the seeds of the WT (left) and mutant $d m c$ (right) at the mature stage; (E) the transverse sections of the top first internodes of the WT (up) and mutant $d m c$ (down); and (F) the internodes of the WT (left) and mutant $d m c$ individuals (right).

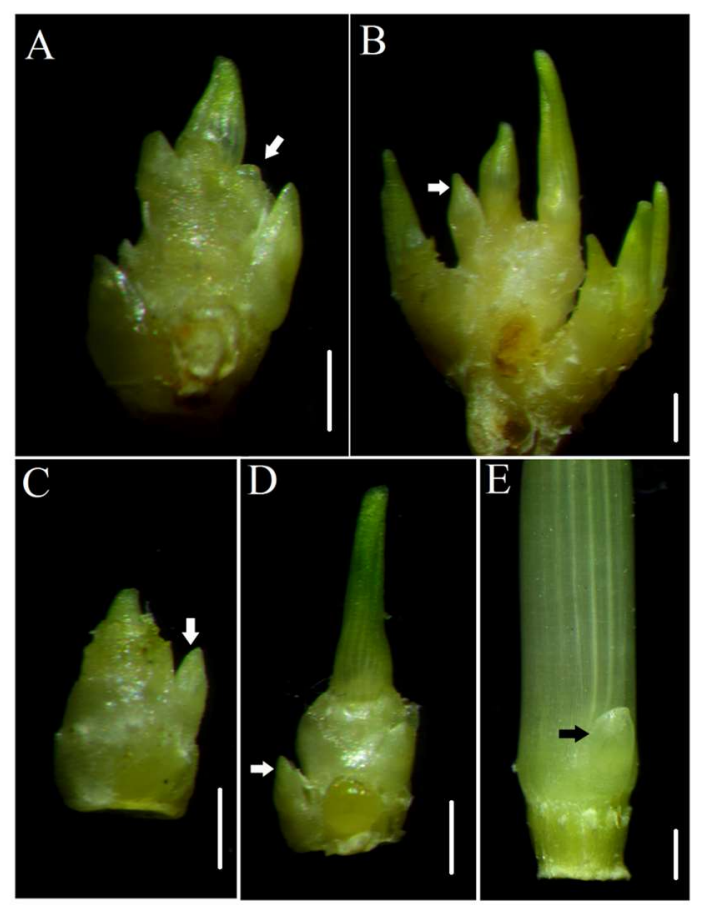

Figure 2. The tiller differentiation of the mutant $d m c$ and WT. The tiller primordia of the WT (A) and mutant $d m c$ (C) at the early tillering stage; the small tillers of the WT (B) and mutant $d m c$ (D) at the middle tillering stage; and only one very small tiller at the basal node of $d m c$ at the elongation stage (E). Arrow heads indicate the tiller primordia or small tillers, scale bar: $2 \mathrm{~mm}$. 
Table 1. Comparison of agronomic traits between the WT and mutant $d m c$.

\begin{tabular}{ccc}
\hline Traits & WT & dmc \\
\hline Plant height/cm & $64.45 \pm 3.28$ & $48.00 \pm 2.63^{* *}$ \\
Spike length/cm & $10.47 \pm 0.53$ & $6.48 \pm 0.90^{* *}$ \\
Internode number of main stem & $5.00 \pm 0$ & $4.18 \pm 0.51^{* *}$ \\
The top first internode length of the main stem/cm & $21.74 \pm 2.28$ & $19.46 \pm 2.37$ \\
The top second internode length of the main stem/cm & $13.98 \pm 0.27$ & $11.21 \pm 1.55^{*}$ \\
The top third internode length of the main stem/cm & $9.42 \pm 0.74$ & $6.48 \pm 0.34^{* *}$ \\
The top fourth internode length of the main stem/cm & $5.78 \pm 0.29$ & $4.24 \pm 0.22^{* *}$ \\
The top fifth internode length of the main stem/cm & $3.19 \pm 0.31$ & - \\
Tiller number & $21.73 \pm 2.20$ & $1.11 \pm 0.3^{* *}$ \\
Spike number & $16.64 \pm 0.92$ & $1.06 \pm 0.32^{* *}$ \\
Spikelet number on the main stem & $21.73 \pm 1.19$ & $14.85 \pm 2.09^{* *}$ \\
Seed number per spike & $64.10 \pm 5.36$ & $34.16 \pm 4.28^{* *}$ \\
1000-grain weight/g & $44.17 \pm 4.59$ & $35.41 \pm 4.34^{* *}$ \\
Heading stage/week & 27 & 28 \\
Anthesis stage/week & 28 & 29 \\
Maturity stage/week & 32 & 33 \\
\hline
\end{tabular}

${ }^{*} p<0.05 ;{ }^{* *} p<0.01$.

\subsection{Genetic Diversity between the WT and Mutant dmc}

To validate whether the $d m c$ was derived from random open pollination in the field, Polymerase Chain Reaction (PCR) amplification of the WT and mutant $d m c$ were carried out with 431 primer pairs of wheat Simple Sequence Repeats (SSR) markers evenly distributed on 21 wheat chromosomes. There was no polymorphic SSR locus between WT and mutant $d m c$ (Figure S2), which demonstrated that their genetic backgrounds were highly consistent. This demonstrated that $d m c$ was a real mutant derived from WT.

\subsection{RNA Sequencing Data}

Six libraries were analyzed using RNA sequencing (mutant $d m c$ : T1, T2, T3; WT: T4, T5, T6). We obtained a total of $68.8 \mathrm{~Gb}$ clean bases and about 463 million reads (single-end reads) (Table S1). The GC contents of the six libraries were $55.84-56.85 \%$, and the average Q30 percentage was $89.25 \%$ (Table S1). Most transcripts were 100 to $300 \mathrm{bp}$ in length (Figure S3), and the biological replicates were highly consistent (Figure S4). The reads were compared with the T. aestivum reference genome. There were 374 million $(80.74 \%)$ reads mapped to the reference genome (Table S2). The average percentage of unique mapped reads was more than $71 \%$ (Table S2). It was clear that a high-quality transcriptome data set was obtained.

\subsection{Annotation and Functional Classification of the Unigenes}

In total, 113,619 unique genes (unigenes) were obtained from the six libraries, and 109,685 unigenes were annotated by BLAST in several databases (Table S3). Furthermore, 10,080 new genes among the 113,619 unigenes were obtained, and 7075 new genes were annotated (Table S4). Functional classification in GO showed that the DEGs were classified into cellular component, molecular function, biological process, and many subcategories. Within the cellular component, molecular function and biological process categories, the most represented DEGs were classified as "cell", "organelle" and "cell part", "catalytic activity", "binding"; "metabolic process", "cellular process" and "single-organism process" (Figure S5).

According to homology unigene distribution of various species in the $\mathrm{Nr}$ database (Figure S6), the order from highest to lowest abundance was Aegilops tauschii, H. vulgare, Triticum urartu, T. aestivum, Brachypodium distachyon, O. sativa, Z. mays, Setaria italica and S. bicolor. 


\subsection{DEGs between the WT and Mutant dmc}

To investigate the gene expression profile variation, a total of 4904 differentially expressed genes (DEGs) between the WT and mutant $d m c$ were identified. Among them, 1506 were expressed at a low level, and 3398 were highly expressed in $d m c$ compared to the WT (Figure 3A). The expression levels of DEGs in $d m c$ and WT are shown as volcano plots (Figure 3B). The expression patterns of DEGs were hierarchically clustered (Figure 3C). The result showed there were significant DEGs, which may be the major genes related to wheat tillering.
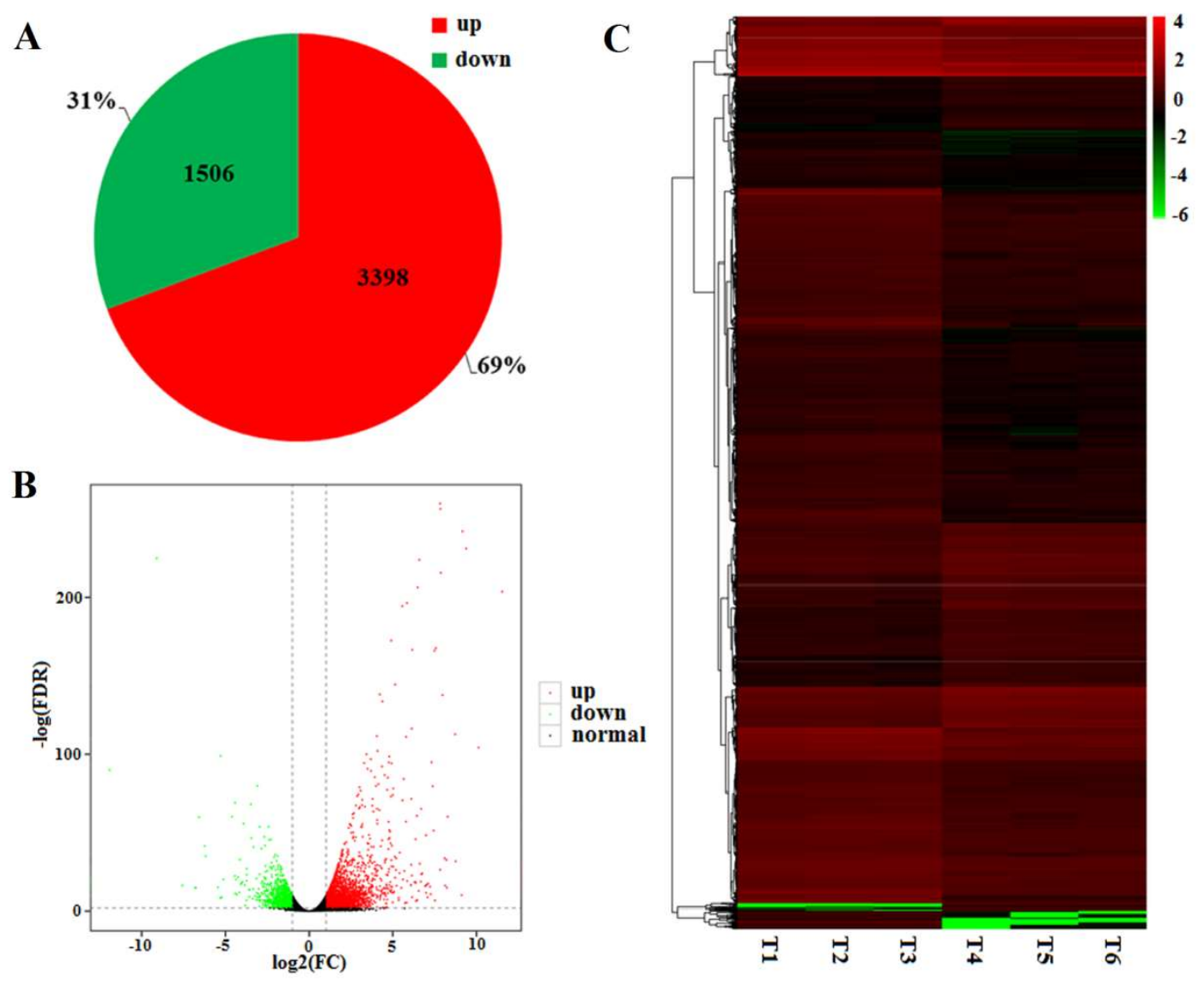

Figure 3. Expression level of DEGs in the mutant $d m c$ compared to WT. (A) Pie chart of DEGs; (B) volcano plots of DEGs. The red and green dots represent genes expressed at high and low levels, respectively, in the mutant $d m c$; FC: Fold Change; FDR; false discovery rate; (C) Heatmap of DEGs. T1, T2, T3: mutant $d m c$; T4, T5, T6: WT. The color scale indicates the $\log _{2}$ FPKM values.

In order to further explore the key genes, significant DEGs ( $\log _{2} \mathrm{FC} \geq 3$ or $\left.\leq-2\right)$ were screened between the mutant $d m c$ and WT (Table S5, Table S6). These DEGs were classified into several groups, such as transcription factor, signal transduction mechanism, and carbohydrate metabolism, etc. Chloroplastic D-3-phosphoglycerate dehydrogenase 2 was the most significant highly expressed gene in the mutant $d m c$; its $\log _{2} \mathrm{FC}$ value was 11.43 . Histone $\mathrm{H} 2 \mathrm{~B} .1$ was the gene that was most significantly expressed at a low level in the mutant $d m c$; its $\log _{2} \mathrm{FC}$ value was 12.28.

\subsection{Functional Classification of the DEGs in GO}

To further explore wheat tiller-related biological pathways or processes, 3991 DEGs were classified into 54 subcategories in the GO database (Figure 4). According to the percentage of DEGs in all genes, the significant subcategories were biological phase (two DEGs), biological adhesion (three DEGs) (belonging to biological process), the membrane part (599 DEGs), the extracellular region (268 DEGs) 
and membrane-enclosed lumen (17 DEGs) (belonging to the cellular component), structural molecule activity (31 DEGs), molecular transducer activity (24 DEGs), receptor (13 DEGs), and protein binding transcription factor (two DEGs) (belonging to molecular function).

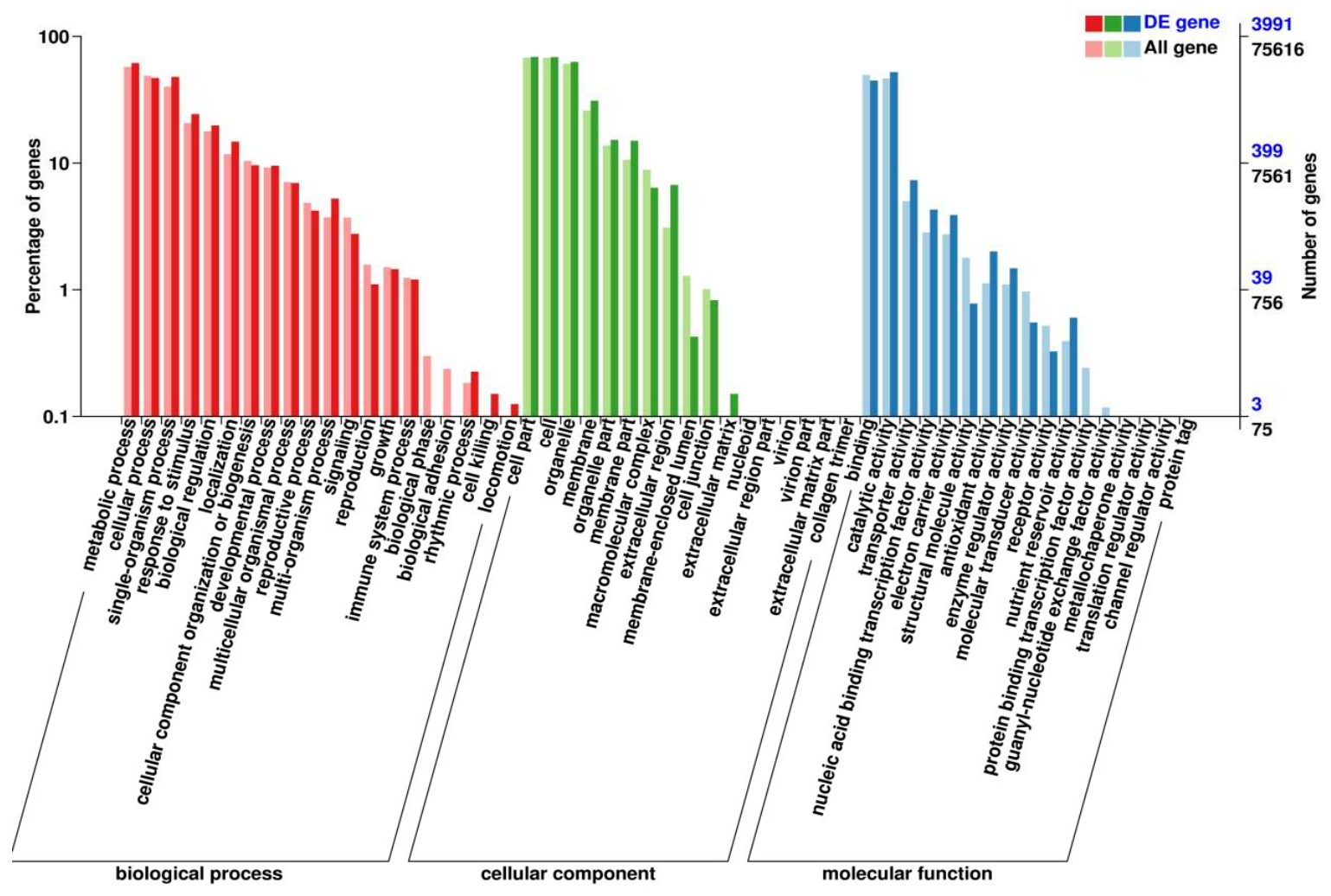

Figure 4. Functional classification of DEGs in the GO database.

\subsection{Pathway Mapping of the DEGs in KEGG}

A total of 979 DEGs were assigned to 112 pathways in KEGG (Table S7). The top ten enriched pathways of enhanced and suppressed DEGs were obtained (Figure 5). The top ten enhanced pathways were phenylpropanoid biosynthesis (ko00940), carbon metabolism (ko01200), photosynthesis (ko00195), starch and sucrose metabolism (ko00500), phenylalanine metabolism (ko00360), photosynthesis-antenna proteins (ko00196), carbon fixation in photosynthetic organisms (ko00710), plant hormone signal transduction (ko04075), biosynthesis of amino acids (ko01230), and glyoxylate and dicarboxylate metabolism (ko000630). In contrast, the top ten suppressed pathways were spliceosome (ko03040), purine metabolism (ko00230), nitrogen metabolism (ko00910), mRNA surveillance pathway (ko03015), RNA degradation (ko03018), zeatin biosynthesis (ko00908), ribosome (ko03010), base excision repair (ko03420), mismatch repair (ko03430), and nucleotide excision repair (ko03420).

The enriched pathways were analyzed by a significance test, and twenty significantly enriched $(Q$ value < 0.2) pathways were obtained in the mutant $d m c$ (Figure 6, Table S8), such as photosynthesis-antenna proteins (ko00196), carbon metabolism (ko01200), carbon fixation in photosynthetic organisms (ko00710), fatty acid elongation (ko00062), butanoate metabolism (ko00650), and phenylpropanoid biosynthesis (ko00940). 


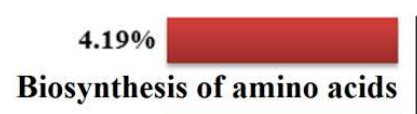

$4.19 \%$

Glyoxylate and dicarboxylate metabolism $4.80 \%$

Plant hormone signal transduction

$\mathbf{5 . 5 2 \%}$

Carbon fixation in photosynthetic organisms

$6.23 \%$

Photosynthesis - antenna proteins $6.54 \%$

Starch and sucrose metabolism

$6.54 \%$

Phenylalanine metabolism

$6.74 \%$

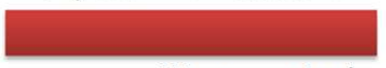

$7.76 \%$

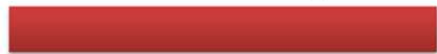

Carbon metabolism

$9.50 \%$

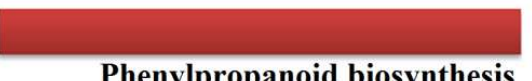

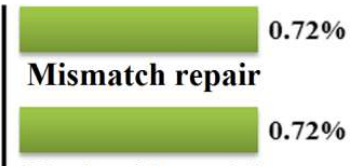

Nucleotide excision repair

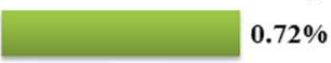

Base excision repair

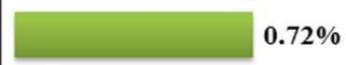

Ribosome

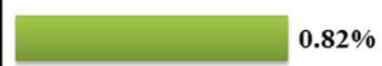

Zeatin biosynthesis

$0.92 \%$

RNA degradation

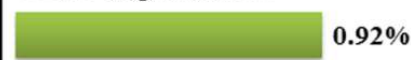

mRNA surveillance pathway

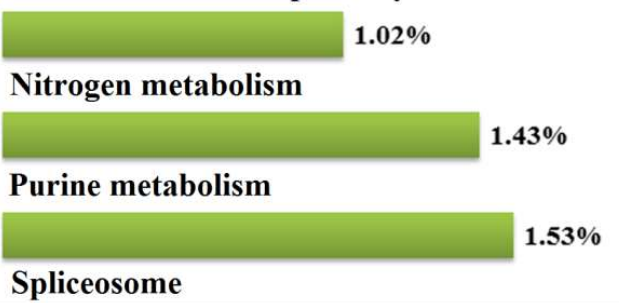

Figure 5. The top ten enhanced and suppressed pathways in the mutant $d m c$ compared to the WT. (Left) The enhanced pathways; (Right) the suppressed pathways. Percentage: The ratio of the number of DEGs annotated to one pathway to the number of DEGs annotated to all pathways.

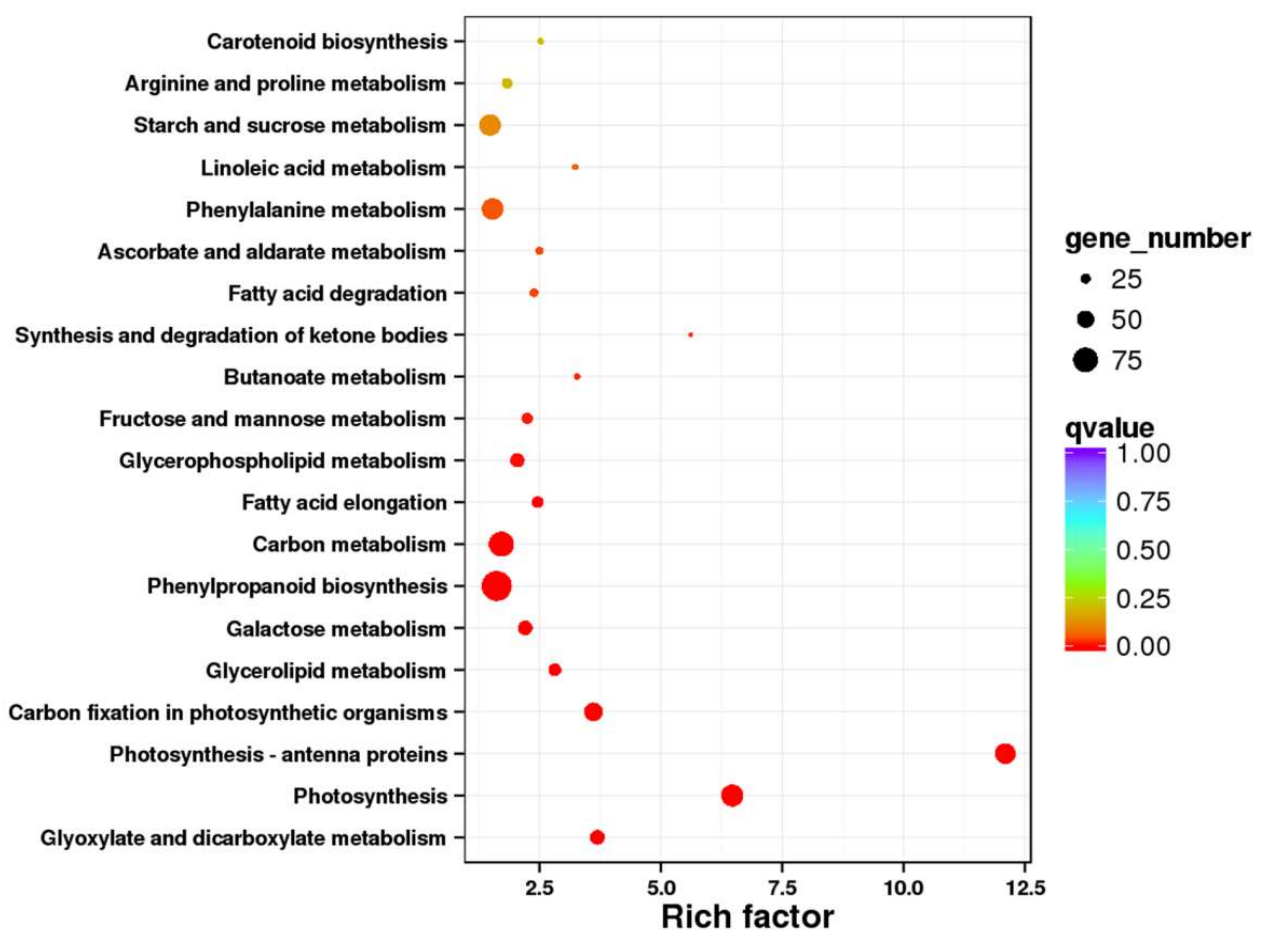

Figure 6. Significance analysis of the enriched pathways. Rich factor: the percentage of A/B. A: The percentage of DEGs annotated to a pathway. B: The percentage of unigenes annotated to a pathway. $Q$ value: corrective $p$ value. 


\subsection{The DEGs Involved in Phytohormone Metabolisms in dmc}

The DEGs involved in plant hormone metabolisms were enriched in the mutant $d m c$, and a total of 83 DEGs were obtained (Figure 7, Table S9). Among them, 52 DEGs were expressed at a low level, and 31 DEGs were highly expressed in the mutant $d m c$ compared to the WT. The DEGs of cytokinin hydroxylase, cytokinin dehydrogenase and cytokinin phosphoribohydrolase were all expressed at a low level (Figure 7C, Table S9); three DEGs of abscisic acid 8'-hydroxylase and abscisic stress-response protein were expressed at a high or low level (Figure 7B, Table S9). Two DEGs of gibberellin 20 oxidase and gibberellin 2-beta-dioxygenase were expressed at a low level (Figure 7D, Table S9); 19 DEGs involved in auxin metabolism were expressed at a low level (Figure 7A, Table S9), 17 DEGs involved in ethylene metabolism were expressed at a low level in the mutant $d m c$ compared to the WT (Table S9). Abscisic stress-responding protein 3 (AA0320460) and auxin-induced protein X15 (AA1998680) were the DEGs that were most significantly expressed at high and low levels, respectively, in the mutant dmc compared to the WT (Table S9).
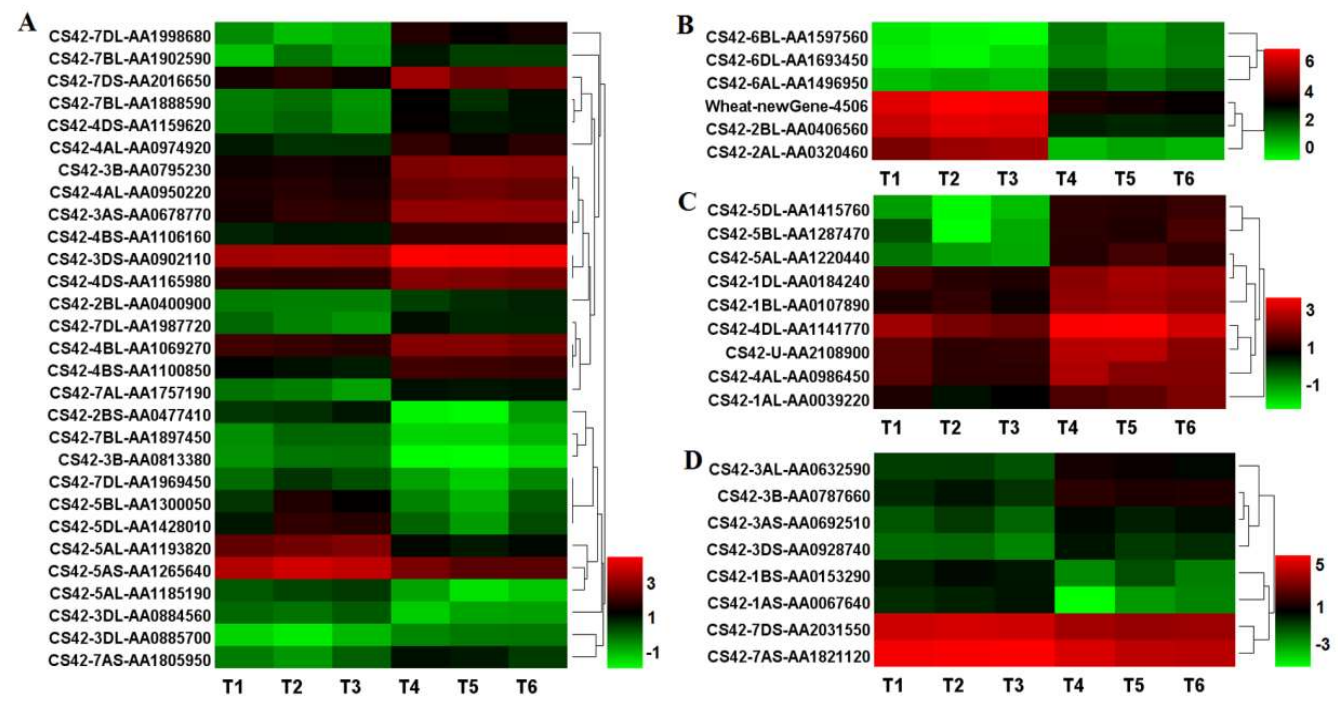

Figure 7. Heatmap of the DEGs involved in plant hormone metabolisms. (A) The DEGs in auxin metabolism; (B) the DEGs in abscisic acid metabolism; (C) the DEGs in cytokinin metabolism; and (D) the DEGs in gibberellin metabolism. T1, T2, T3: mutant dmc; T4, T5, T6: WT The color scale indicates the $\log _{2}$ FPKM values.

\subsection{The DEGs Related to Carbohydrate Metabolism in the Mutant dmc}

A total of 303 DEGs related to carbohydrate metabolism were obtained and they were divided into 19 groups (Figure 8A, Table S10). Among these, the DEGs related to the metabolism of glucose, fructose, starch, fucose, ribulose, mannose, xlanase, glucoside, galactoside, galactinol and galacturonokinase were all highly expressed in $d m c$ (Figure 8A, Table S10). The DEGs related to metabolisms of glucan, xyloglucan, sucrose, sugar, amylase, glucosidase, glycosyltransferase, and polygalacturonase were simultaneously expressed at high or low levels in $d m c$. Furthermore, the percentages of DEGs expressed at low levels were lower than those of the highly-expressed DEGs in all carbohydrate metabolisms (Figure 8A, Table S10).

\subsection{Transcription Factor Type DEGs in the Mutant dmc}

A total of 35 significant DEGs of transcription factors $\left(\log _{2} \mathrm{FC} \geq 3\right.$ or $\left.\leq-2\right)$ were obtained in $d m c$ (Figure 8B, Table S5, Table S6), and they belonged to zinc finger protein, heat stress transcription factor, NAC domain-containing protein, WRKY transcription factor, ethylene-responsive transcription factor and MADS-box protein families, etc. Among these DEGs regulated by transcription factors (Figure 8B, Table S11), an SPX domain-containing membrane protein Os02g45520 (AA1610920) was the most 
significantly highly expressed, and probable WRKY transcription factor 12 (AA0534130) was the DEG that was most significantly expressed at a low level in the mutant $d m c$ compared to the WT. The DEGs belonging to families B3, DBB, Dof, GRF, LBD, LFY, MADS, SRS, and WOX were only expressed at low levels; the DEGs belonging to families GATA, GRA, and NF-YC were only expressed at high levels in the mutant $d m c$ compared to the WT (Figure 8B, Table S11). The most enriched transcription factor family was ERF, followed by MYB, bHLH and HSF (Figure 8B, Table S11).

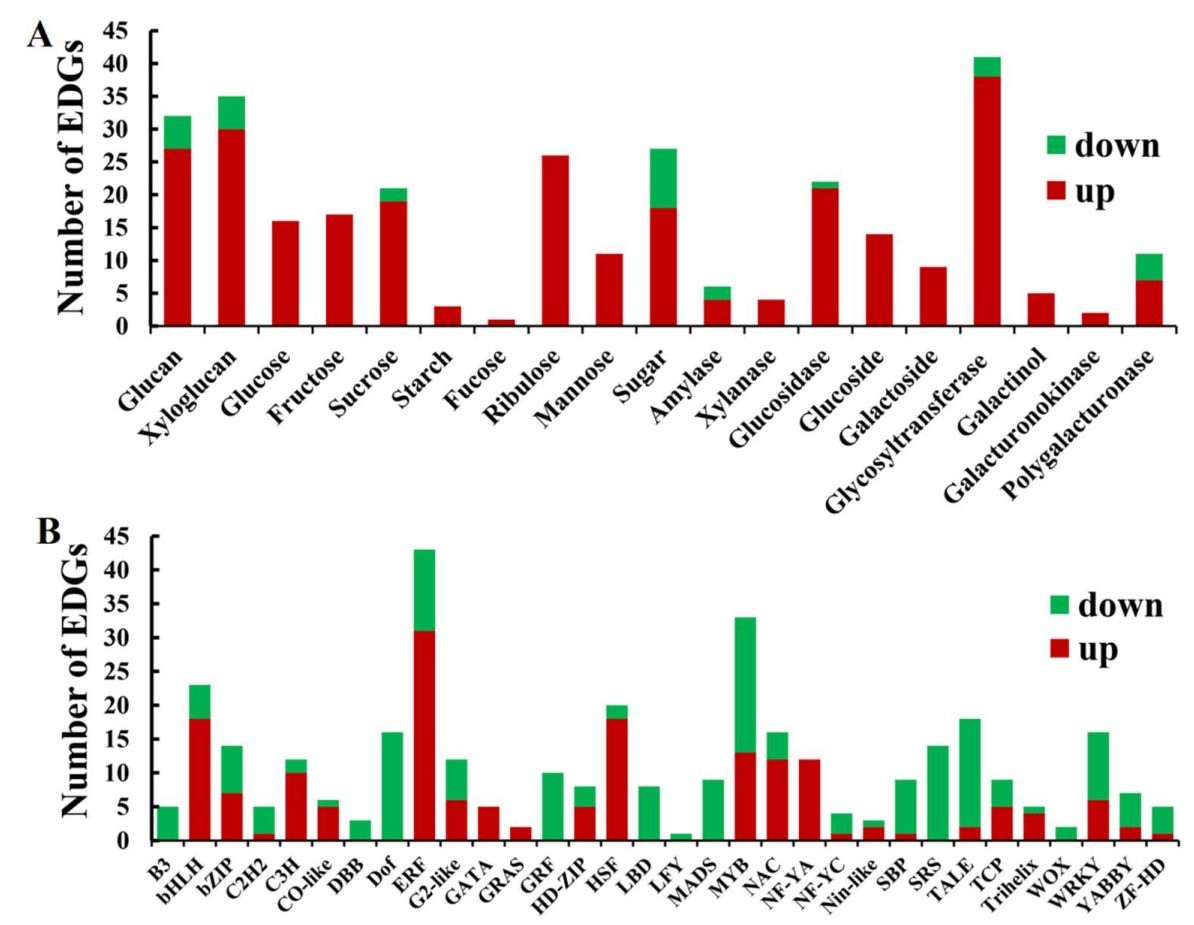

Figure 8. A bar chart of the DEGs involved in carbohydrate metabolisms and the transcription factors. (A) Classification of the DEGs involved in carbohydrate metabolisms. $x$-axis: the subcategories of carbohydrate metabolisms, $y$-axis: the number of DEGs in each subcategory; (B) Classification of the differentially-expressed transcription factors. $x$-axis: The subfamilies of transcription factors, $y$-axis: the number of DEGs in each family of transcription factors. Red: highly-expressed DEGs; green: DEGs expressed at a low level.

\subsection{The DEGs Related to Signaling Processes}

A total of 390 DEGs related to signal transduction were obtained (Table S12). Among these DEGs, signal transduction NRT1/PTR family protein genes occupied the largest percentage (8.72\%), followed by F-box protein (5.13\%), E3 ubiquitin-protein ligase (5.13\%), pentatricopeptide repeat-containing protein $(4.62 \%)$, CBL-interacting protein kinase $(4.36 \%)$ and cysteine-rich receptor-like protein kinase $(3.85 \%)$ (Table S12). The growth regulating factor, leucine-rich repeat extensin-like protein, phytosulfokine receptor, protein G1-like, protein reveille, protein short internodes and protein $\mathrm{SHI}$ related sequence genes were all expressed at low levels. Ankyrin repeat domain-containing protein, basic 7S globulin 2 low molecular weight subunit, CBL-interacting protein kinase 14, NAC domain-containing protein, and pectinesterase were almost always highly expressed (Table S12).

\subsection{Expression Profiles of Twelve Genes in Wheat Tiller Primordia}

To demonstrate the reliability of the sequencing results, we selected twelve of the significant DEGs to perform real-time qRT-PCR. Linear regression analysis showed that the results of the transcriptome analysis were reliable (Figure 9, Figure S7). 

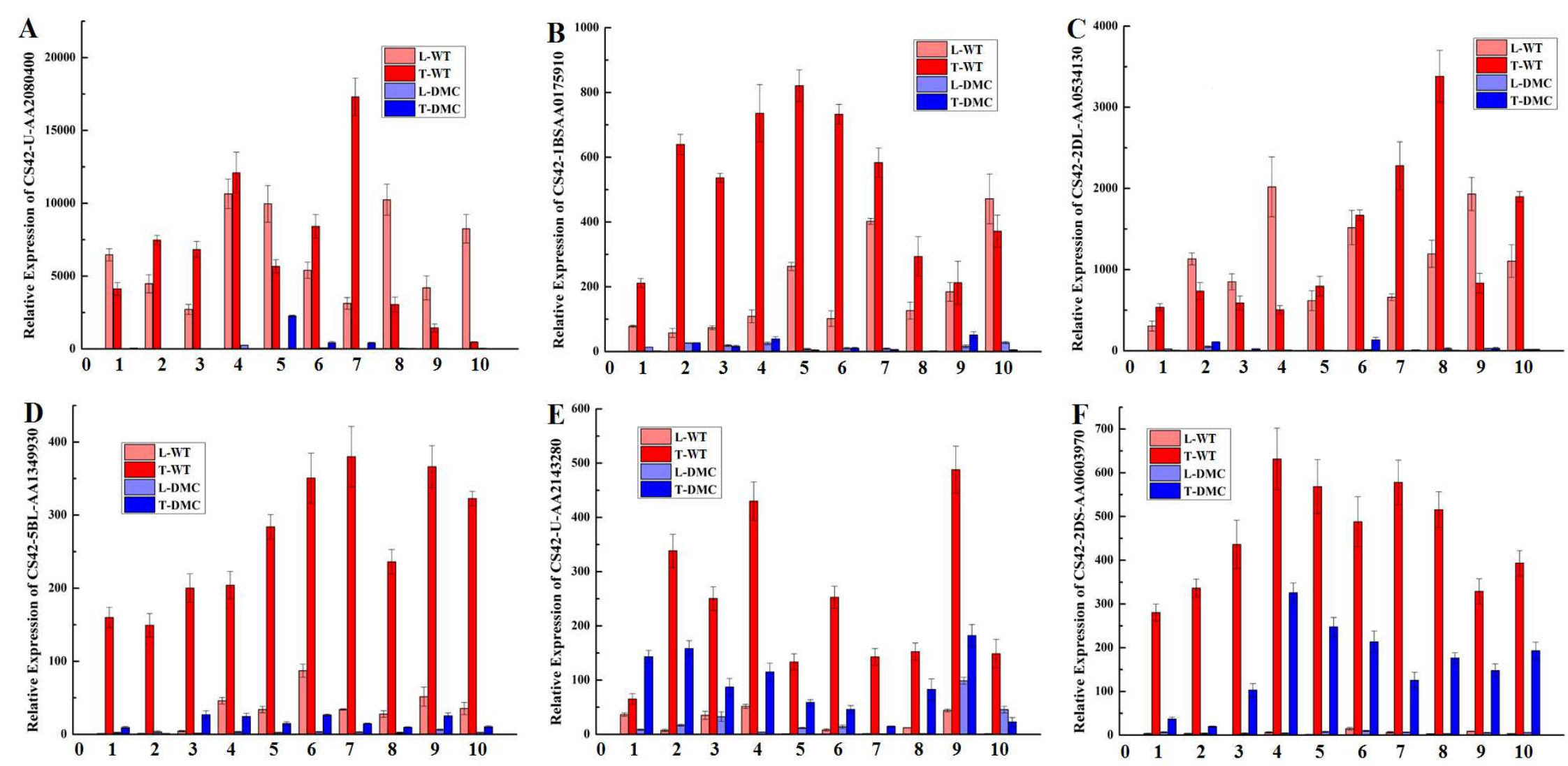

Figure 9. Cont. 


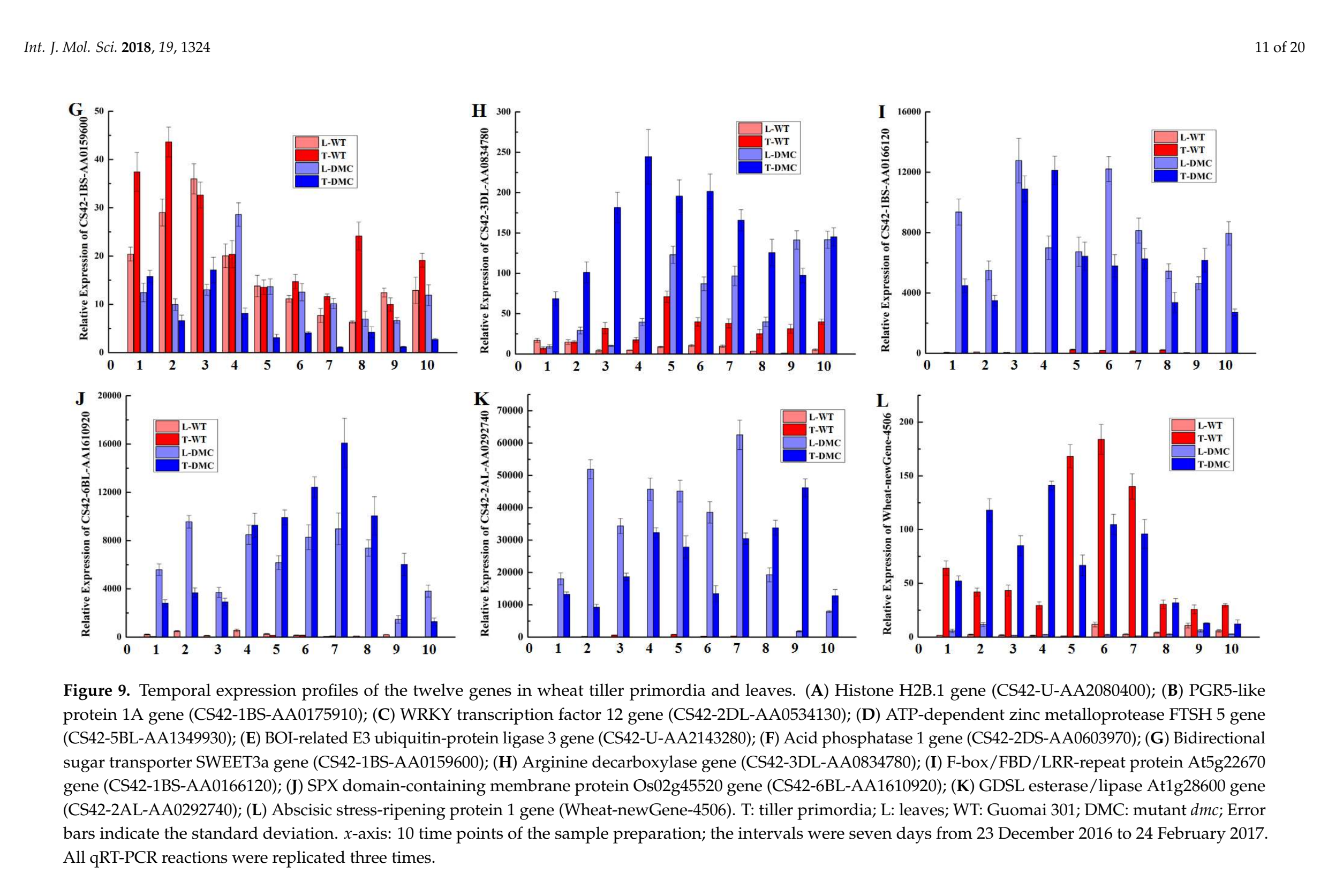


A histone H2B.1 gene (CS42-U-AA2080400, Figure 9A), a PGR5-like protein 1A gene (CS42-1BS-AA0175910, Figure 9B) and a WRKY transcription factor 12 gene (CS42-2DL-AA0534130, Figure 9C) were significantly suppressed in tiller primordia of $d m c$, and these three genes were also significantly suppressed in the leaves of $d m c$ compared to the WT. Mutation significantly suppressed the expression of an ATP-dependent zinc metalloprotease FTSH 5 gene (CS42-5BL-AA1349930, Figure 9D), a BOI-related E3 ubiquitin-protein ligase 3 gene (CS42-U-AA2143280, Figure 9E), an acid phosphatase 1 gene (CS42-2DS-AA0603970, Figure 9F) and a bidirectional sugar transporter SWEET3a gene (CS42-1BS-AA0159600, Figure 9G) in tiller primordia of $d m c$; these four genes were specifically expressed in tiller primordia compared to leaves except the bidirectional sugar transporter SWEET3a gene (CS42-1BS-AA0159600, Figure 9G). The expression of an arginine decarboxylase gene (CS42-3DL-AA0834780, Figure 9H); a putative F-box/FBD/LRR-repeat protein At5g22670 gene (CS42-1BS-AA0166120, Figure 9I); a SPX domain-containing membrane protein Os02g45520 gene (CS42-6BL-AA1610920, Figure 9J); and a GDSL esterase/lipase At1g28600 gene (CS42-2AL-AA0292740, Figure $9 \mathrm{~K}$ ) were significantly activated in tiller primordia of $d m c$ compared to $\mathrm{WT}$, and their expression profiles in leaves of $d m c$ were also similar. The expression of an abscisic stress-response protein 1 gene (Wheat-newGene-4506, Figure 9L) was irregular. The twelve genes were either only just expressed or completely suppressed in tiller primordia of $d m c$. The results suggested that these genes played important roles in the tiller development of wheat.

\section{Discussion}

\subsection{Lack of Vitality in the Mutant dmc}

The morphology of the mutant $d m c$ was dwarfish, with yellowish cotyledons and almost no tillers, which demonstrated its lack of vitality. The phenotype of the mutant $d m c$ was novel. In wheat, the leaves of the tiller inhibition mutants tin3 and ftin were much darker than the WT plants [1,4]; however, the leaves of the mutant $d m c$ were yellowish. Both spikes and seed were much larger in the mutant tin3 [1] compared with the mutant $d m c$. Normally, there is a highly negative correlation between tiller number and plant height in rice and wheat [6]. In wheat, NAUH167, a high-tillering mutant was dwarfish compared to the WT [6], the plant height of the tiller inhibition mutant ftin was slightly higher than that of the WT [4], the phenotype of the mutant $d m c$ was not the same as NAUH167 or ftin, and the mutant $d m c$ was not only dwarfish but also had almost no tillers. The mutant $d m c$ had fewer tiller primordia. Most of the primordia could not grow or stopped developing, which resulted in no tillers. Though most DEGs related to photosynthesis were highly expressed in $d m c$, this occurred in contrast to its lower vitality and biomass.

\subsection{Auxin and Cytokinin Metabolisms Were Suppressed in dmc}

Phytohormones play essential roles in plant growth and development throughout the vegetative to reproductive stages [40-43]. Tillering is a key developmental event in wheat, which needs a balanced phytohormone metabolism to maintain normal tillering [44-46].

In Arabidopsis, auxin can inhibit bud outgrowth in the highly branched shoot mutant axr1, and the effect of auxin on the wild type is more obvious [47]. In rice, a knock-down mutant of OsIAA6 produces more tillers due to the regulation of the auxin transporter OsPIN1 [48]. However, a further study found that auxin does not enter the lateral buds [49,50], and this phenomenon can be supported by cytokinin and strigolactone [50,51]. In Arabidopsis, cytokinin acts to overcome auxin-mediated apical dominance, allowing buds to evade apical dominance [52]. In this study, we obtained 29 DEGs related to auxin metabolism, and 19 DEGs were expressed at a low level (Figure 6, Table S9): the level of auxin in the mutant $d m c$ might be low; however, this might not be consistent with the premise that auxin inhibits bud outgrowth. The KEGG pathway of zeatin biosynthesis (ko00908; Figure S8) was suppressed, and the suppressed differentially expressed zeatin biosynthesis genes were adenylate isopentenyltransferase 1 (chloroplastic), three cytokinin hydroxylases, and three cytokinin 
dehydrogenases (Figure S8, Table S9). Furthermore, the plant hormone signal transduction genes (ko04075; Figure S9) in KEGG showed that the expression of zeatin biosynthesis can affect cytokinin biosynthesis: the expression of downstream signal transduction components and the two-component response regulator $(A R R)$ were down-regulated (Figure S9). This result is in agreement with a previous study on rice, which indicated that a high level of cytokinin can increase the tiller number [53].

Interestingly, overexpressing gibberellin 2-oxidases (GA20x) can produce more tillers in rice [54]. Gibberellin localization in vascular tissue is required to control auxin-dependent bud outgrowth in hybrid aspen (Pterocarya stenoptera) [55]. Gibberellin is also required for cytokinin-mediated axillary bud outgrowth in Jatropha curcas [56]. In this study, two DEGs encoding gibberellin 20 oxidase 2, and DEGs encoding gibberellin 2-beta-dioxygenase 1 and gibberellin 3-beta-dioxygenase 2-1, which were expressed at low levels, were obtained (Figure 6, Table S9), and the possible high level of gibberellin could be consistent with the mutant $d m c$ not tillering. The hormone regulation of wheat tillers is very complex, and further research is needed in the future.

The plant height of the mutant $d m c$ was decreased significantly. It was about $74.53 \%$ of the WT height (Figure 1A). Many plant hormones can promote plant growth, like auxin [42], gibberellin [57,58], and cytokinin [59]. The suppressed expression of genes involved in auxin, zeatin and cytokinin metabolisms (Figure S9) may be the key causes accounting for dwarfism of the mutant $d m c$.

\subsection{Carbohydrate Metabolism and Phenylpropanoid Biosynthesis Were Active in dmc}

Many studies have demonstrated that sugar can regulate bud growth [60-62]. In wheat, the phenotype of the tiller inhibition mutant $(\mathrm{tin})$ was associated with precocious internode elongation; further study showed that the mutant tin transferred sucrose away from buds to elongating internodes [61]. In pea (Pisum sativum), total sucrose levels were significantly increased in node 2 buds after decapitation; the axillary buds were rapidly released in intact plants supplemented with external sucrose [60]. Sugar also affects bud outgrowth in rose (Rosa sp.) [62,63]. In this study, the enriched pathways of starch and sucrose metabolism (ko00500) in KEGG were significantly activated (Figure 5, Figure 8A). Two DEGs related to sucrose synthase were expressed at a low level, and nine DEGs related to sucrose 1-fructosyltransferase, which were expressed at a high level, were obtained (Figure 7, Table S10). The potentially higher activities of the corresponding enzymes may decrease the content of small molecular carbohydrates, which may inhibit wheat tillering.

Interestingly, phenylpropanoid biosynthesis (ko00940; Figure S10) was the most enhanced pathway in KEGG, which regulates the biosyntheses of different lignins such as syringyl, guaiacyl, p-hydroxy-phenyl, and 5-hydroxy-guaiacyl lignins. A total of 93 annotated DEGs belonged to the phenylpropanoid biosynthesis (Figure S10), and among them 56 were various peroxidases (Table S10) which likely suppressed the biosyntheses of lignins, and the concentration of lignins in the mutant might be low. This result might be consistent with the dwarf phenotype of the mutant dmc. 1-aminocyclopropane-1-carboxylic acid oxidase (ACCO) catalyzes the final step of ethylene biosynthesis. In this study, seven DEGs of ACCO and seven DEGs of ACCO homologs were obtained, and they might affect the biosynthesis of ethylene in $d m c$.

\subsection{Some Transcription Factors Are Suppressed in dmc}

Transcription factors (TFs) play essential roles in plant leaf [64], flower [65], and branch [66] growth and development.

In maize (Zea mays), the Knotted1-like homeobox (KNOX) TFs up-regulates GA2ox1 [67]. In this study, four DEGs of knotted-1-like 1, three knotted-1-like 12 and three KNOX3 (TALE family) were obtained, and they were all expressed at a low level, and these might down-regulate the expression of GA2ox1 and inhibit tillering in the mutant $d m c$ (Figure 8, Table S11). This observation is in agreement with the observation that overexpressing GA2ox produced more tillers in rice [54]. In rice, overexpression of growth-regulating factors OsGRF3 and OsGRF10 reduces tillers. The expression of Oskn2, one rice KNOX gene, was down-regulated by overexpression of OsGRF3 [68]. In this study, 
one DEG homologous to TFs GRF2, GRF10, and GRF12; two DEGs homologous to GRF1 and GRF5; three DEGs homologous to GRF9 were obtained (GRF family), however, they were all expressed at a low level in $d m c$ (Figure 8, Table S11). The relationship between GRFs expressed at a low level and the phenotype of the mutant $d m c$ needs further study.

DWARF TILLER1, a WUSCHEL-related homeobox (WOX) TFs, is a positive regulator of tiller growth in rice [66]. In rice, the completely sterile and reduced tillering 1 mutant (srt1) was caused by a mutation in WUSCHEL (OsWUS, one member of the WOX gene family). The homeobox domain of SRT1 is essential for tillering [69]. In this study, two DEGs homologous to TFs WOX 4 (WOX family) were expressed at a low level in $d m c$ (Figure 8, Table S11), which might affect the tillering of $d m c$. Furthermore, The DEGs of TF families B3, DBB, Dof, GRF, LBD, LFY, MADS and SRS were only expressed at a low level (Figure 8, Table S11); they might affect the tillering of $d m c$.

\subsection{Signal Transduction and Photosynthesis in dmc}

Signal transduction is related to many pathways and metabolic processes. In Arabidopsis, short internodes (SHI) is a suppressor of GA responses [70]. In this study, six DEGs associated with short internodes, expressed at a low level, were obtained, and they might promote GA responses in the $d m c$ mutant that does not produce tillers. The larger percentage of DEGs related to E3 ubiquitin-protein ligase, NRT1/PTR FAMILY, F-box protein, pentatricopeptide repeat-containing protein and E3 ubiquitin-protein ligase (Table S12) might also affect the tillering and plant growth of the mutant $d m c$.

Photosynthesis (ko00195; Figure S11) was the third most enhanced pathway in the mutant $d m c$ (Figure 4), and photosystem I, photosystem II, cytochrome b6/f complex, photosynthethic electron transport and F-type ATPase related to photosynthesis were all highly expressed (Figure S11).

The enhanced expression of the photosynthetic components did not correspond with the phenotype of the mutant $d m c$, which requires further study.

\section{Materials and Methods}

\subsection{Plant Materials and Growth Conditions}

The wheat cultivar 'Guomai 301' was bred in our laboratory. Wheat cultivar "Guomai 301" has medium tillers, but a high percentage of earbearing tillers. The tillering ability of the WT conformed to the requirements of high-yield wheat breeding, which ensures a relatively dense population (600-700 spikes per hectare) and large spikes with more grains (36.1-37.4 grains per spike). In October 2012, the seeds of the WT were treated with EMS and planted at the Shangqiu Experimental Farm, Henan Province, China ( $34^{\circ} 25^{\prime} \mathrm{N}, 115^{\circ} 39^{\prime} \mathrm{E}, 49 \mathrm{~m}$ a.s.l.). The mutant $d m c$ was obtained from the $\mathrm{M}_{2}$ generation in 2013. Thereafter, to eliminate the background mutations, $d m c$ plants were individually selected generation by generation; normal plants in the segregating line were also selected as the control (CK in line; WT) simultaneously. In 2016, the WT and $d m c$ were planted at the Experimental Farm of Henan Agricultural University, Zhengzhou, Henan Province, China ( $34^{\circ} 51^{\prime} \mathrm{N}, 113^{\circ} 35^{\prime} \mathrm{E}, 95 \mathrm{~m}$ a.s.l.). The lines were sown in plots of $3.0 \mathrm{~m}$ in length and $2.0 \mathrm{~m}$ in width; the distance between rows was $0.25 \mathrm{~m}$, and 20 seeds were planted in each row [71]. The samples for transcriptome sequencing analysis were prepared in 2017.

\subsection{Trait Measurements, Morphology Observations and SSR Analysis}

The tiller number, spike number, plant height, and internode number of the main stem, among other traits (Table 1), of $d m c$ and the WT were observed and measured. Each sample was prepared by random selection of more than 20 individuals of $d m c$ and the WT. The statistical tests were performed using Student's $t$-test, and the variation was expressed as the standard deviation (SD).

The tillers of the mutant $d m c$ and WT were observed from the early tillering stage with an inverted microscope (Olympus 3111286), and the images were captured by a camera (Nikon Coolpix 4500). 
The outer leaves and sheaths were removed to show the tiller primordia and very small tillers at the seedling stage with an anatomical needle. The large tillers at the adult plant stage were observed by the naked eye.

A set of microsatellite assays was applied to evaluate the genetic diversity among the WT and mutant $d m c$. The SSR primers (Appendix) employed in this study included those of GDM [72], WMC [73], etc. Genomic DNAs of the WT and mutant $d m c$ were extracted from leaves with the CTAB method [74]. The PCR reactions were performed in $10 \mu \mathrm{L}$ volumes containing $5 \mu \mathrm{L}$ EasyTaq ${ }^{\circledR}$ PCR SuperMix for PAGE $(2 \times)$ (TransGen Biotech, Beijing, China), $1 \mu \mathrm{L}$ primer mix $(10 \mu \mathrm{M}), 0.5 \mu \mathrm{L}$ DNA

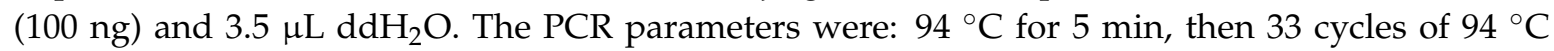
for $30 \mathrm{~s}, 50-60{ }^{\circ} \mathrm{C}$ (based on primer annealing temperature) for $30 \mathrm{~s}$ and $72{ }^{\circ} \mathrm{C}$ for $60 \mathrm{~s}$, and a final elongation at $72{ }^{\circ} \mathrm{C}$ for $10 \mathrm{~min}$. PCR products were separated in $8 \%$ non-denatured polyacrylamide gels (acrylamide:bisacrylamide $=19: 1)$ at room temperature. Each sample $(2 \mu \mathrm{L})$ was loaded and run in $1 \times$ TBE (90 mmol L-1 Tris-borate, 2 mmol L-1 of EDTA, $\mathrm{pH}$ 8.3) buffer at $90 \mathrm{~W}$ for $1 \mathrm{~h}$, then visualized by silver staining [75].

\subsection{RNA Extraction, Library Preparation and Sequencing}

Tiller primordial samples (Figure S1) were dissected at the three-leaf stage to four-leaf stage. Two super bulk samples of the mutant $d m c$ (T1, T2, and T3) and WT (T4, T5, and T6) with three biological replicates were prepared. Each bulk sample included more than ten independent individuals.

RNA was extracted using Trizol reagent (TransGen Biotech, Beijing, China) according to the manufacturer's protocol. RNA concentration was measured using a NanoDrop 2000 (NanoDrop Technologies, Wilmington, DE, USA). RNA integrity was assessed using the RNA Nano 6000 Assay Kit on the Agilent Bioanalyzer 2100 system (Agilent Technologies, Santa Clara, CA, USA).

The RNA bulk samples were prepared with $1 \mu \mathrm{g}$ RNA per individual. Sequencing libraries were constructed using NEBNext UltraTM RNA Library Prep Kit for Illumina (NEB, Ipswich, MA, USA) following the manufacturer's recommendations. The preferential cDNA fragments were $240 \mathrm{bp}$ in length. The correlation among biological replicates was analyzed using Pearson's Correlation Coefficient (r) [76]. The six cDNA libraries were sequenced with Illumina HiSeq Xten from Biomarker Biotechnology Corporation (Beijing, China).

\subsection{Transcriptome Analyses}

The clean reads were compared with the T. aestivum reference genome [77] using TopHat2 [78]. The unigenes were annotated by BLAST [79] in Nr (NCBI non-redundant protein sequences), $\mathrm{Nt}$ (NCBI non-redundant nucleotide sequences), Pfam (protein family), KOG/COG (Clusters of Orthologous Groups of proteins), Swiss-Prot (a manually annotated and reviewed protein sequence database), KO (KEGG Ortholog database), and GO (Gene Ontology) databases. To explore new transcripts and genes in the mutant $d m c$, the reads were assembled using Cufflinks software [80] based on the reference genome sequence, and the transcriptional intervals that had not been annotated were searched for and compared with the original genome annotation information. The KEGG Orthology of the new genes was analyzed using KOBAS2.0 [81], and the amino acid sequences of the new genes were predicted; finally, the new genes were annotated using HMMER [82], referring to the numerous databases. The standard gene expression levels were expressed as fragments per kilobase of transcript per million fragments mapped (FPKM) [83]. Differentially-expressed genes (DEGs) were identified by DEseq [84] with a false discovery rate (FDR) $<0.01$ and a fold change value $(\mathrm{FC}) \geq 2$.

\section{5. $q R T-P C R$}

The tiller primordia and leaf samples of the mutant $d m c$ and guomai 301 were prepared at 10 time points for real-time qRT-PCR; the intervals of the 10 time points were seven days from 23 December 2016 to 24 February 2017. Twelve DEGs were selected to test and verify the sequencing data by qRT-PCR. The primers were designed using Primer Premier 5.0 (Table S13). The wheat actin gene was 
used as an internal control gene. The qRT-PCR reactions were performed in $20 \mu \mathrm{L}$ volumes containing $10 \mu \mathrm{L}$ TransStart ${ }^{\circledR}$ Top Green Qpcr SuperMix $(2 \times)$ (TransGen Biotech, Beijing, China), $2 \mu \mathrm{L}$ primer mix

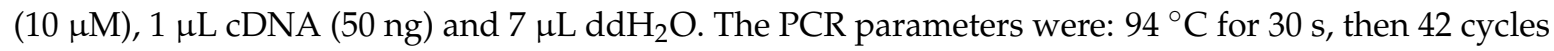
of $94{ }^{\circ} \mathrm{C}$ for $5 \mathrm{~s}, 60^{\circ} \mathrm{C}$ for $30 \mathrm{~s}$. All qRT-PCR reactions were replicated three times. The gene expression levels were calculated according to the $2^{-\Delta \Delta C t}$ method [85].

\subsection{Ethical Approval}

This article does not contain any studies with human participants or animals performed by any of the authors.

Wheat (Triticum aestivum L.) plants were used in this study. The wheat cultivar 'Guomai 301' was bred in our laboratory.

The wheat mutant $d m c$ was selected from EMS treated Guomai 301 in our laboratory.

\section{Conclusions}

Transcriptomes of the tiller primordia from the wheat non-tiller mutant $d m c$ and WT Guomai 301 were integratively analyzed. We identified a set of genes related to wheat tiller differentiation. Sixty-nine percent of significant DEGs (FC $\geq 2$ ) were highly expressed and $31 \%$ were expressed at a low level in $d m c$. Phenylpropanoid biosynthesis (ko00940; Figure S10) had the most highly expressed DEGs (9.50\%). Carbohydrate-related metabolisms consisted of the largest highly-expressed DEG group, including photosynthesis $(6.74 \%)$, starch and sucrose metabolism $(6.54 \%)$, photosynthesis-antenna proteins $(6.23 \%)$, carbon fixation in photosynthetic organisms $(5.52 \%)$, carbon metabolism $(7.76 \%)$, and galactose metabolism (4.09\%). The majority of genes that were expressed at a low level belonged to the classes of DNA replication, transcription, and translation, as well as zeatin synthesis. Functional model analysis indicated that variations in carbohydrate metabolism, phytohormones and transcription factors were the major causes of non-tillering in $d m c$. Synthesis and lower expression of genes related to protein synthesis, auxin, zeatin and cytokinine; syntheses enhanced the expression of genes involved in the biosynthesis of abscisic acid, gibberellins, and ethylene syntheses, consistent with the phenotype of $d m c$. The expression profiles of TF homologs, knotted-1-like 1, homeobox protein knotted-1-like 12 and KNOX3, and WOX 4 were also consistent with the phenotype of $d m c$. Other issues need further study, such as the relationship between phenylpropanoid biosynthesis, photosynthesis, variations of different phytohormone concentrations and the phenotype of $d m c$.

Supplementary Materials: Supplementary materials can be found at http:/ /www.mdpi.com/1422-0067/19/5/ 1324/s1.

Author Contributions: R.H. performed all the experiments pertaining to trait observation, photograph taking, sample preparation, and qRT-PCR and also analyzed the data and drafted the manuscript. Y.N. treated Guomai 301 with EMS and found the mutant. J.L. helped with sowing and sample preparation. Z.J. helped with sowing, trait observation and figure drawing. X.Z. contributed to sowing and data analysis. Y.J. contributed to the field experiments. Q.L. contributed to the field experiments and maintenance of the wheat accessions. J.N. designed the whole study and drafted the manuscript and gave the final approval to the version of the manuscript that is being sent for consideration for publication.

Acknowledgments: This study was supported by the National Natural Science foundation of China (NSFC, 31571646) and The Special Fund for Key Agricultural Projects in Henan Province, China, in 2016 (161100110400).

Conflicts of Interest: The authors declare that the research was conducted in the absence of any commercial or financial relationships that could be construed as a potential conflict of interest.

\section{References}

1. Kuraparthy, V.; Sood, S.; Dhaliwal, H.S.; Chhuneja, P.; Gill, B.S. Identification and mapping of a tiller inhibition gene (tin3) in wheat. Theor. Appl. Genet. 2007, 114, 285-294. [CrossRef] [PubMed]

2. Naruoka, Y.; Talbert, L.E.; Lanning, S.P.; Blake, N.K.; Martin, J.M.; Sherman, J.D. Identification of quantitative trait loci for productive tiller number and its relationship to agronomic traits in spring wheat. Theor. Appl. Genet. 2011, 123, 1043-1053. [CrossRef] [PubMed] 
3. Spielmeyer, W.; Richards, R.A. Comparative mapping of wheat chromosome 1AS which contains the tiller inhibition gene (tin) with rice chromosome 5S. Theor. Appl. Genet. 2004, 109, 1303-1310. [CrossRef] [PubMed]

4. Zhang, J.; Wu, J.; Liu, W.; Lu, X.; Yang, X.; Gao, A.; Li, X.; Lu, Y.; Li, L. Genetic mapping of a fertile tiller inhibition gene, ftin, in wheat. Mol. Breed. 2013, 31, 441-449. [CrossRef]

5. Peng, Z.S.; Yen, C.; Yang, J.L. Genetic control of oligo-culms character in common wheat. Wheat Inf. Serv. 1998, 86, 19-24.

6. Xu, T.; Bian, N.; Wen, M.; Xiao, J.; Yuan, C.; Cao, A.; Zhang, S.; Wang, X.; Wang, H. Characterization of a common wheat (Triticum aestivum L.) high-tillering dwarf mutant. Theor. Appl. Genet. 2017, 130, 483-494. [CrossRef] [PubMed]

7. Dabbert, T.; Okagaki, R.J.; Cho, S.; Heinen, S.; Boddu, J.; Muehlbauer, G.J. The genetics of barley low-tillering mutants: Low number of tillers-1 (lnt1). Theor. Appl. Genet. 2010, 121, 705-715. [CrossRef] [PubMed]

8. Dabbert, T.; Okagaki, R.J.; Cho, S.; Boddu, J.; Muehlbauer, G.J. The genetics of barley low-tillering mutants: Absent lower laterals (als). Theor. Appl. Genet. 2009, 118, 1351-1360. [CrossRef] [PubMed]

9. Babb, S.; Muehlbauer, G.J. Genetic and morphological characterization of the barley uniculm2 (cul2) mutant. Theor. Appl. Genet. 2003, 106, 846-857. [CrossRef] [PubMed]

10. Jiang, H.; Guo, L.B.; Xue, D.W.; Zeng, D.L.; Zhang, G.H.; Dong, G.J.; Gu, M.H.; Qian, Q. Genetic analysis and gene-mapping of two reduced-culm-number mutants in rice. J. Integr. Plant Biol. 2006, 48, 341-347. [CrossRef]

11. Fujita, D.; Ebron, L.A.; Araki, E.; Kato, H.; Khush, G.S.; Sheehy, J.E.; Lafarge, T.; Fukuta, Y.; Kobayashi, N. Fine mapping of a gene for low-tiller number, $L t n$, in japonica rice (Oryza sativa L.) variety Aikawa 1. Theor. Appl. Genet. 2010, 120, 1233-1240. [CrossRef] [PubMed]

12. Zhou, Y.; Zhu, J.; Li, Z.; Gu, F.; Zhang, H.; Tang, S.; Gu, M.; Liang, G. Fine mapping and cloning of MT1, a novel allele of D10. Prog. Nat. Sci. 2009, 19, 1683-1689. [CrossRef]

13. Shah, M.M.; Gill, K.S.; Baenziger, P.S.; Yen, Y.; Kaeppler, S.M.; Ariyarathne, H.M. Molecular mapping of loci for agronomic traits on chromosome 3A of bread wheat. Crop Sci. 1999, 39, 1728-1732. [CrossRef]

14. Kato, K.; Miura, H.; Sawada, S. Mapping QTLs controlling grain yield and its components on chromosome 5A of wheat. Theor. Appl. Genet. 2000, 101, 1114-1121. [CrossRef]

15. Li, W.L.; Nelson, J.C.; Chu, C.Y.; Shi, L.H.; Huang, S.H.; Liu, D.J. Chromosomal locations and genetic relationships of tiller and spike characters in wheat. Euphytica 2002, 125, 357-366. [CrossRef]

16. Wang, Z.; Liu, Y.; Shi, H.; Mo, H.; Wu, F.; Lin, Y.; Gao, S.; Wang, J.; Wei, Y.; Liu, C.; et al. Identification and validation of novel low-tiller number QTL in common wheat. Theor. Appl. Genet. 2016, 129, 603-612. [CrossRef] [PubMed]

17. Chen, P.; Jiang, L.; Yu, C.; Zhang, W.; Wang, J.; Wan, J. The identification and mapping of a tiller angle QTL on rice chromosome 9. Crop Sci. 2008, 48, 1799-1806. [CrossRef]

18. Yu, B.; Lin, Z.; Li, H.; Li, X.; Li, J.; Wang, Y.; Zhang, X.; Zhu, Z.; Zhai, W.; Wang, X.; et al. TAC1, a major quantitative trait locus controlling tiller angle in rice. Plant J. 2007, 52, 891-898. [CrossRef] [PubMed]

19. Liu, G.; Zhu, H.; Liu, S.; Zeng, R.; Zhang, Z.; Li, W.; Ding, X.; Zhao, F.; Zhang, G. Unconditional and conditional QTL mapping for the developmental behavior of tiller number in rice (Oryza sativa L.). Genetica 2010, 138, 885-893. [CrossRef] [PubMed]

20. Hoffmann, A.; Maurer, A.; Pillen, K. Detection of nitrogen deficiency QTL in juvenile wild barley introgression lines growing in a hydroponic system. BMC Genet. 2012, 13, 88. [CrossRef] [PubMed]

21. Naz, A.A.; Arifuzzaman, M.; Muzammil, S.; Pillen, K.; Léon, J. Wild barley introgression lines revealed novel QTL alleles for root and related shoot traits in the cultivated barley (Hordeum vulgare L.). BMC Genet. 2014, 15, 107. [CrossRef] [PubMed]

22. Malyshev, S.; Korzun, V.; Voylokov, A.; Smirnov, V.; Borner, A. Linkage mapping of the mutant loci in rye (Secale cereale L.). Theor. Appl. Genet. 2001, 103, 70-74. [CrossRef]

23. Stirnberg, P.; Van, D.S.K.; Leyser, H.M. MAX1 and MAX2 control shoot lateral branching in Arabidopsis. Development 2002, 129, 1131-1141. [PubMed]

24. Booker, J.; Sieberer, T.W.; Williamson, L.; Willett, B.; Stirnberg, P.; Turnbull, C.; Srinivasan, M.; Goddard, P.; Leyser, O. MAX1 encodes a cytochrome P450 family member that acts downstream of MAX3/4 to produce a carotenoid-derived branch-inhibiting hormone. Dev. Cell 2005, 8, 443-449. [CrossRef] [PubMed] 
25. Sorefan, K.; Booker, J.; Haurogné, K.; Goussot, M.; Bainbridge, B.; Foo, E.; Chatfield, S.; Ward, S.; Beveridge, Q.C.; Rameau, C.; et al. MAX4 and RMS1 are orthologous dioxygenase-like genes that regulate shoot branching in Arabidopsis and pea. Gene Dev. 2003, 17, 1469-1474. [CrossRef] [PubMed]

26. Booker, J.; Auldridge, M.; Wills, S.; McCarty, D.; Klee, H.; Leyser, O. MAX3/CCD7 is a carotenoid cleavage dioxygenase required for the synthesis of a novel plant signaling molecule. Curr. Biol. 2004, 14, 1232-1238. [CrossRef] [PubMed]

27. Li, X.; Qian, Q.; Fu, Z.; Wang, Y.; Xiong, G.; Zeng, D.; Wang, X.; Liu, X.; Teng, S.; Hiroshi, F.; et al. Control of tillering in rice. Nature 2003, 422, 618-621. [CrossRef] [PubMed]

28. Sun, F.; Zhang, W.; Xiong, G.; Yan, M.; Qian, Q.; Li, J.; Wang, Y. Identification and functional analysis of the MOC1 interacting protein 1. J. Genet. Genom. 2010, 37, 69-77. [CrossRef]

29. Xu, C.; Wang, Y.; Yu, Y.; Duan, J.; Liao, Z.; Xiong, G.; Meng, X.; Liu, G.; Qian, Q.; Li, J. Degradation of MONOCULM 1 by APC/C (TAD1) regulates rice tillering. Nat. Commun. 2012, 3, 750. [CrossRef] [PubMed]

30. Takeda, T.; Suwa, Y.; Suzuki, M.; Kitano, H.; Ueguchi-Tanaka, M.; Ashikari, M.; Matsuoka, M.; Ueguchi, C. The OsTB1 gene negatively regulates lateral branching in rice. Plant J. 2003, 33, 513-520. [CrossRef] [PubMed]

31. Ramsay, L.; Comadran, J.; Druka, A.; Marshall, D.F.; Thomas, W.T.; Macaulay, M.; MacKenzie, K.; Simpson, C.; Fuller, J.; Bonar, N.; et al. INTERMEDIUM-C, a modifier of lateral spikelet fertility in barley, is an ortholog of the maize domestication gene TEOSINTE BRANCHED 1. Nat. Genet. 2011, 43, 169-172. [CrossRef] [PubMed]

32. Chono, M.; Honda, I.; Zeniya, H.; Yoneyama, K.; Saisho, D.; Takeda, K.; Takatsuto, S.; Hoshino, T.; Watanabe, Y. A semidwarf phenotype of barley uzu results from a nucleotide substitution in the gene encoding a putative brassinosteroid receptor. Plant Physiol. 2003, 133, 1209-1219. [CrossRef] [PubMed]

33. Liu, J.; Cheng, X.; Liu, P.; Sun, J. miR156-Targeted SBP-Box transcription factors interact with DWARF53 to regulate TEOSINTE BRANCHED1 and BARREN STALK1 expression in bread wheat. Plant Physiol. 2017, 174, 1931-1948. [CrossRef] [PubMed]

34. Lewis, J.M.; Mackintosh, C.A.; Shin, S.; Gilding, E.; Kravchenko, S.; Baldridge, G.; Zeyen, R.; Muehlbauer, G.J. Overexpression of the maize Teosinte Branched1 gene in wheat suppresses tiller development. Plant Cell Rep. 2008, 27, 1217-1225. [CrossRef] [PubMed]

35. Zhu, X.X.; Li, Q.Y.; Shen, C.C.; Duan, Z.B.; Yu, D.Y.; Niu, J.S.; Ni, Y.J.; Jiang, Y.M. Transcriptome analysis for abnormal spike development of the wheat mutant dms. PLoS ONE 2016, 11, e0149287. [CrossRef] [PubMed]

36. Wang, L.; Hua, Q.; Ma, Y.; Hu, G.; Qin, Y. Comparative transcriptome analyses of a late-maturing mandarin mutant and its original cultivar reveals gene expression profiling associated with citrus fruit maturation. PeerJ. 2017, 5, e3343. [CrossRef] [PubMed]

37. Xu, K.; Sun, F.; Chai, G.; Wang, Y.; Shi, L.; Liu, S.; Xi, Y. De novo assembly and transcriptome analysis of two contrary tillering mutants to learn the mechanisms of tillers outgrowth in switchgrass (Panicum virgatum L.). Front. Plant Sci. 2015, 6, 749. [CrossRef] [PubMed]

38. Wang, Y.; Zeng, X.; Peal, L.; Tang, Y.; Wu, Y.; Mahalingam, R. Transcriptome analysis of nodes and buds from high and low tillering switchgrass inbred lines. PLoS ONE 2013, 8, e83772. [CrossRef] [PubMed]

39. Kebrom, T.H.; Mullet, J.E. Transcriptome profiling of tiller buds provides new insights into PhyB regulation of tillering and indeterminate growth in sorghum. Plant Physiol. 2016, 170, 2232-2250. [CrossRef] [PubMed]

40. Shan, X.; Yan, J.; Xie, D. Comparison of phytohormone signaling mechanisms. Curr. Opin. Plant Biol. 2012, 15, 84-91. [CrossRef] [PubMed]

41. Wang, Y.; Li, J. Molecular basis of plant architecture. Annu. Rev. Plant Biol. 2008, 59, 253-279. [CrossRef] [PubMed]

42. Mcsteen, P. Auxin and monocot development. CSH. Perspect. Biol. 2010, 2, a001479. [CrossRef] [PubMed]

43. Yamaguchi, S. Gibberellin metabolism and its regulation. Annu. Rev. Plant Biol. 2008, 59, 225-251. [CrossRef] [PubMed]

44. Hussien, A.; Tavakol, E.; Horner, D.S.; Muñoz-Amatriaín, M.; Muehlbauer, G.J.; Rossini, L. Genetics of tillering in rice and barley. Plant Genome 2014, 7, 93-113. [CrossRef]

45. Janssen, B.J.; Drummond, R.S.; Snowden, K.C. Regulation of axillary shoot development. Curr. Opin. Plant Biol. 2014, 17, 28-35. [CrossRef] [PubMed]

46. Kebrom, T.H.; Spielmeyer, W.; Finnegan, E.J. Grasses provide new insights into regulation of shoot branching. Trends Plant Sci. 2013, 18, 41-48. [CrossRef] [PubMed]

47. Stirnberg, P.; Chatfield, S.P.; Leyser, H.M.O. AXR1 acts after lateral bud formation to inhibit lateral bud growth in Arabidopsis. Plant Physiol. 1999, 121, 839-847. [CrossRef] [PubMed] 
48. Jung, H.; Lee, D.K.; Choi, Y.D.; Kim, J.K. OsIAA6, a member of the rice Aux/IAA gene family, is involved in drought tolerance and tiller outgrowth. Plant Sci. 2015, 236, 304-312. [CrossRef] [PubMed]

49. Booker, J.; Chatfield, S.; Leyser, O. Auxin acts in xylem-associated or medullary cells to mediate apical dominance. Plant Cell 2003, 15, 495-507. [CrossRef] [PubMed]

50. Ferguson, B.J.; Beveridge, C.A. Roles for auxin, cytokinin, and strigolactone in regulating shoot branching. Plant Physiol. 2009, 149, 1929-1944. [CrossRef] [PubMed]

51. Crawford, S.; Shinohara, N.; Sieberer, T.; Williamson, L.; George, G.; Hepworth, J.; Müller, D.; Domagalska, M.A.; Leyser, O. Strigolactones enhance competition between shoot branches by dampening auxin transport. Development 2010, 137, 2905-2913. [CrossRef] [PubMed]

52. Müller, D.; Waldie, T.; Miyawaki, K.; To, J.P.; Melnyk, C.W.; Kieber, J.J.; Kakimoto, T.; Leyser, Y. Cytokinin is required for escape but not release from auxin mediated apical dominance. Plant J. 2015, 82, 874-886. [CrossRef] [PubMed]

53. Yeh, S.Y.; Chen, H.W.; Ng, C.Y.; Lin, C.Y.; Tseng, T.H.; Li, W.H.; Ku, M.S. Down-regulation of cytokinin oxidase 2 expression increases tiller number and improves rice yield. Rice 2015, 8, 36. [CrossRef] [PubMed]

54. Lo, S.F.; Yang, S.Y.; Chen, K.T.; Hsing, Y.I.; Zeevaart, J.A.; Chen, L.J.; Yu, S.M. A novel class of gibberellin 2-oxidases control semidwarfism, tillering, and root development in rice. Plant Cell 2008, 20, 2603-2618. [CrossRef] [PubMed]

55. Mauriat, M.; Sandberg, L.G.; Moritz, T. Proper gibberellin localization in vascular tissue is required to control auxin-dependent leaf development and bud outgrowth in hybrid aspen. Plant J. 2011, 67, 805-816. [CrossRef] [PubMed]

56. Ni, J.; Gao, C.; Chen, M.S.; Pan, B.Z.; Ye, K.; Xu, Z.F. Gibberellin promotes shoot branching in the perennial woody plant Jatropha curcas. Plant Cell Physiol. 2015, 56, 1655-1666. [CrossRef] [PubMed]

57. Sun, T. The molecular mechanism and evolution of the GA-GID1-DELLA signaling module in plants. Curr. Biol. 2011, 21, R338-R345. [CrossRef] [PubMed]

58. Wang, Y.; Du, Y.; Yang, Z.; Chen, L.; Condon, A.G.; Hu, Y. Comparing the effects of GA-responsive dwarfing genes Rht13, and Rht8, on plant height and some agronomic traits in common wheat. Field Crop Res. 2015, 179, 35-43. [CrossRef]

59. Perilli, S.; Moubayidin, L.; Sabatini, S. The molecular basis of cytokinin function. Curr. Opin. Plant Biol. 2010, 13, 21-26. [CrossRef] [PubMed]

60. Mason, M.G.; Ross, J.J.; Babst, B.A.; Wienclaw, B.N.; Beveridge, C.A. Sugar demand, not auxin, is the initial regulator of apical dominance. Proc. Natl. Acad. Sci. USA 2014, 111, 6092-6097. [CrossRef] [PubMed]

61. Kebrom, T.H.; Chandler, P.M.; Swain, S.M.; King, R.W.; Richards, R.A.; Spielmeyer, W. Inhibition of tiller bud outgrowth in the tin mutant of wheat is associated with precocious internode development. Plant Physiol. 2012, 160, 308-318. [CrossRef] [PubMed]

62. Rabot, A.; Henry, C.; Baaziz, K.B.; Mortreau, E.; Azri, W.; Lothier, J.; Hamama, L.; Boummaza, R.; Leduc, N.; Pelleschi-Travier, S.; et al. Insight into the role of sugars in bud burst under light in the rose. Plant Cell Physiol. 2012, 53, 1068-1082. [CrossRef] [PubMed]

63. Barbier, F.; Péron, T.; Lecerf, M.; Perez-Garcia, M.D.; Barrière, Q.; Rolčík, J.; Boutet-Mercey, S.; Citerne, S.; Lemoine, R.; Porcheron, B.; et al. Sucrose is an early modulator of the key hormonal mechanisms controlling bud outgrowth in Rosa hybrida. J. Exp. Bot. 2015, 66, 2569-2582. [CrossRef] [PubMed]

64. Zhang, M.; Hu, X.; Zhu, M.; Xu, M.; Wang, L. Transcription factors NF-YA2 and NF-YA10 regulate leaf growth via auxin signaling in Arabidopsis. Sci. Rep. UK 2017, 7, 1395. [CrossRef] [PubMed]

65. Theißen, G.; Melzer, R.; Rümpler, F. MADS-domain transcription factors and the floral quartet model of flower development: Linking plant development and evolution. Development 2016, 143, 3259-3271. [CrossRef] [PubMed]

66. Wang, W.; Li, G.; Zhao, J.; Chu, H.; Lin, W.; Zhang, D.; Wang, Z.; Liang, W. Dwarf Tiller1, a Wuschel-related homeobox transcription factor, is required for tiller growth in rice. PLoS Genet. 2014, 10, e1004154. [CrossRef] [PubMed]

67. Bolduc, N.; Hake, S. The maize transcription factor KNOTTED1 directly regulates the gibberellin catabolism gene ga2ox1. Plant Cell 2009, 21, 1647-1658. [CrossRef] [PubMed]

68. Kuijt, S.J.; Greco, R.; Agalou, A.; Shao, J.; ‘t Hoen, C.C.J.; Overnas, E.; Osnato, M.; Curiale, S.; Meynard, D.; Gulik, R.V.; et al. Interaction between the GROWTH-REGULATING FACTOR and KNOTTED1-LIKE HOMEOBOX families of transcription factors. Plant Physiol. 2014, 164, 1952-1966. [CrossRef] [PubMed] 
69. Mjomba, F.M.; Zheng, Y.; Liu, H.; Tang, W.; Hong, Z.; Wang, F.; Wu, W. Homeobox is pivotal for OsWUS controlling tiller development and female fertility in rice. G3 Genes Genom. Genet. 2016, 6, 2013-2021. [CrossRef] [PubMed]

70. Fridborg, I.; Kuusk, S.; Robertson, M.; Sundberg, E. The Arabidopsis protein SHI represses gibberellin responses in Arabidopsis and barley. Plant Physiol. 2001, 127, 937-948. [CrossRef] [PubMed]

71. Duan, Z.B.; Shen, C.C.; Li, Q.Y.; Lü, G.Z.; Ni, Y.J.; Yu, D.Y.; Niu, J.S. Identification of a novel male sterile wheat mutant $d m s$ conferring dwarf status and multi-pistils. J. Integr. Agric. 2015, 14, 1706-1714. [CrossRef]

72. Pestsova, E.; Ganal, M.W.; Röder, M.S. Isolation and mapping of microsatellite markers specific for the D genome of bread wheat. Genome 2000, 43, 689-697. [CrossRef] [PubMed]

73. Somers, D.; Isaac, P.; Edwards, K. A high-density microsatellite consensus map for bread wheat (Triticum aestivum L.). Theor. Appl. Genet. 2004, 109, 1105-1114. [CrossRef] [PubMed]

74. Cota-Sánchez, J.H.; Remarchuk, K.; Ubayasena, K. Ready-to-use DNA extracted with a CTAB method adapted for herbarium specimens and mucilaginous plant tissue. Plant Mol. Biol. Rep. 2006, 24, 161-167. [CrossRef]

75. Bassam, B.J.; Caetanoanollés, G.; Gresshoff, P.M. Fast and sensitive silver staining of DNA in polyacrylamide gels. Anal. Biochem. 1991, 196, 80-83. [CrossRef]

76. Schulze, S.K.; Kanwar, R.; Gölzenleuchter, M.; Therneau, T.M.; Beutler, A.S. SERE: Single-parameter quality control and sample comparison for RNA-Seq. BMC Genom. 2012, 13, 524. [CrossRef] [PubMed]

77. The Triticum aestivum Genome Sequence. Available online: http://ftp.ensemblgenomes.org/pub/plants/ release-32/fasta/triticum_aestivum/. (accessed on 2 October 2017).

78. Kim, D.; Pertea, G.; Trapnell, C.; Pimentel, H.; Kelley, R.; Salzberg, S.L. TopHat2: Accurate alignment of transcriptomes in the presence of insertions, deletions and gene fusions. Genome Biol. 2013, 14, R36. [CrossRef] [PubMed]

79. Altschul, S.F.; Madden, T.L.; Schäffer, A.A.; Zhang, J.; Zhang, Z.; Miller, W.; Lipman, D.J. Gapped BLAST and PSI BLAST: A new generation of protein database search programs. Nucleic Acids Res. 1997, 25, 3389-3402. [CrossRef] [PubMed]

80. Trapnell, C.; Williams, B.A.; Pertea, G.; Mortazavi, A.; Kwan, G.; Baren, M.J.; Salzberg, S.L.; Wold, B.J.; Pachter, L. Transcript assembly and quantification by RNA Seq reveals unannotated transcripts and isoform switching during cell differentiation. Nat. Biotechnol. 2010, 28, 511-515. [CrossRef] [PubMed]

81. Xie, C.; Mao, X.; Huang, J.; Ding, Y.; Wu, J.; Dong, S.; Kong, L.; Gao, G.; Li, C.Y.; Li, L. KOBAS 2.0: A web server for annotation and identification of enriched pathways and diseases. Nucleic Acids Res. 2011, 39, W316-W322. [CrossRef] [PubMed]

82. Eddy, S.R. Profile hidden Markov models. Bioinformatics 1998, 14, 755-763. [CrossRef] [PubMed]

83. Florea, L.; Song, L.; Salzberg, S.L. Thousands of exon skipping events differentiate among splicing patterns in sixteen human tissues. F1000Research 2013, 2, 188. [CrossRef] [PubMed]

84. Wang, L.; Feng, Z.; Wang, X.; Wang, X.; Zhang, X. DEGseq: An R package for identifying differentially expressed genes from RNA-seq data. Bioinformatics 2010, 26, 136-138. [CrossRef] [PubMed]

85. Livak, K.J.; Schmittgen, T.D. Analysis of relative gene expression data using real-time quantitative PCR and the $2^{-\Delta \Delta C T}$ method. Methods 2001, 25, 402-408. [CrossRef] [PubMed]

(c) 2018 by the authors. Licensee MDPI, Basel, Switzerland. This article is an open access article distributed under the terms and conditions of the Creative Commons Attribution (CC BY) license (http://creativecommons.org/licenses/by/4.0/). 